\title{
Evaluation of the suitability of the Waterloo Membrane Sampler for sample preconcentration before compound-specific isotope analysis
}

\author{
O. Goli ${ }^{a}$, T. Górecki ${ }^{\mathrm{a}, *}$, H.T. Mugammar $^{\mathrm{b}}$, M. Marchesi ${ }^{\mathrm{b}}$, R. Aravena ${ }^{\mathrm{b}}$ \\ ${ }^{a}$ Department of Chemistry, University of Waterloo, Waterloo, ON, N2L 3G1 Canada \\ ${ }^{\mathrm{b}}$ Department of Earth and Environmental Sciences, University of Waterloo, Waterloo, ON, N2L 3G1 Canada
}

\section{H I G H L I G H T S}

- The suitability of the WMS for analyte preconcentration before CSIA was examined.

- The results were consistently reproducible.

- WMS introduced small, constant and reproducible isotopic fractionation.

- Fractionation was independent of temperature, exposure time and analyte amount.

- WMS can be used to collect gas samples from the unsaturated zone for CSIA.

\section{A R T I C L E I N F O}

\section{Article history:}

Received 22 March 2016

Received in revised form 18 January 2017

Accepted 1 February 2017

Available online 3 February 2017

\section{Keywords:}

Compound-specific isotope analysis

Analyte preconcentration

Passive sampling

Waterloo Membrane Sampler

\author{
G R A P H I C A L A B S T R A C T
}

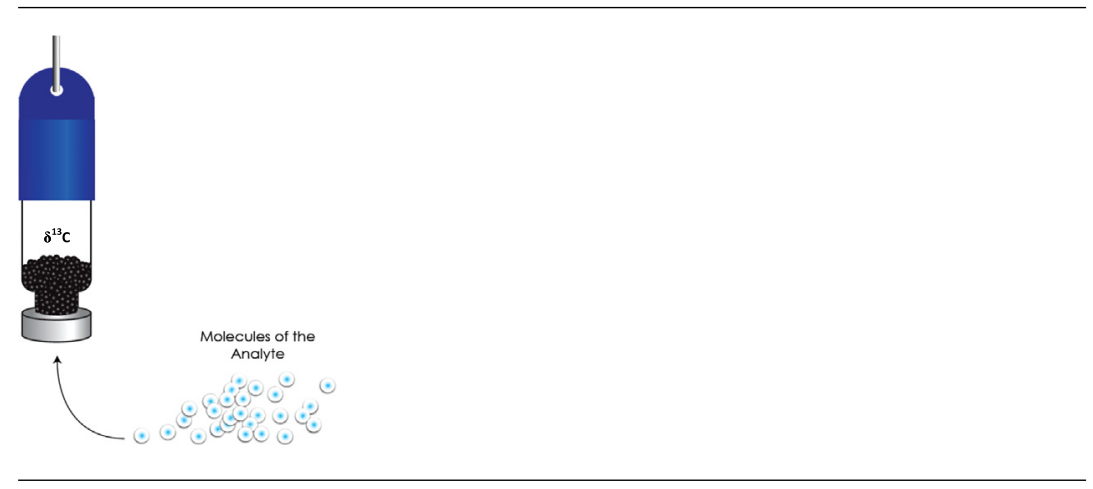

\section{A B S T R A C T}

Compound-specific isotope analysis (CSIA) has been used extensively for fingerprinting applications and for the evaluation of the degradation processes in organic contaminant studies in groundwater. Recently, the potential applications of CSIA in unsaturated and vapour intrusion studies have been explored. A key challenge in these studies is the development of analytical protocols for CSIA that can handle the very low concentrations of organic compounds typically found in the unsaturated zone and indoor samples. The objective of this research was to evaluate the applicability of the Waterloo Membrane Sampler (WMS) for CSIA, with intended applications in the unsaturated zone and in vapour intrusion studies. Tests were performed to evaluate isotope effects associated with sorption and desorption of the analytes under active sampling and passive sampling conditions. A standard gas mixture containing three model analytes, hexane, benzene and trichloroethene, was used in the experiments. Tests were designed to evaluate the isotope effect as a function of the time of exposure ( 3 to 192 hours), amount of analytes

\footnotetext{
Presented in part at the CleanUp 2015 Conference, Sept. 13-16, 2015, Melbourne, Australia.

* Corresponding author. Fax: +1 5197460435.

E-mail address: tgorecki@uwaterloo.ca (T. Górecki).
} 
sorbed, and exposure temperature $\left(25^{\circ} \mathrm{C}\right.$ and $\left.12^{\circ} \mathrm{C}\right)$. The results obtained in all studies showed very good reproducibility with standard deviations within the accepted analytical error of $\pm 0.5 \%$. The data also showed that the $\delta^{13} \mathrm{C}$ values of the analytes collected by passive sampling were more depleted than the values obtained by active sampling. However, the degree of fractionation, ranging from 0.4 to $1.4 \%$, was practically constant and independent of the sampling time, mass adsorbed and temperature in the ranges of variables studied. The lowest concentrations that could be detected were $0.65 \mathrm{mg} / \mathrm{m}^{3}$ for hexane, $0.88 \mathrm{mg} / \mathrm{m}^{3}$ benzene and $4.38 \mathrm{mg} / \mathrm{m}^{3}$ for TCE. The method developed was applied in a field study where the results obtained for benzene and toluene collected in the unsaturated zone showed the expected values compared to carbon isotope data obtained for benzene and toluene at the water table. Results obtained in this study confirmed good data reproducibility. This indicates that CSIA coupled with WMS has the potential to become a valuable tool in unsaturated zone studies and in the environmental forensics field.

(C) 2017 Elsevier B.V. All rights reserved.

\section{Introduction}

Compound-specific isotope analysis (CSIA) is a widely used analytical approach in fingerprinting studies and for evaluating degradation of organic compounds under natural conditions and during remediation (Chartrand et al., 2005; Blessing et al., 2009; Lojkasek-Lima et al., 2012a,b). While most of the published work involved groundwater, several studies have been carried out to evaluate processes that affect attenuation of contaminants in the unsaturated zone (Bouchard et al., 2008; Hunkeler et al., 2011; Patterson et al., 2014). Due to environmental concerns related to vapour intrusion of organic compounds into buildings, some efforts have been directed towards testing the use of CSIA for forensic applications in vapour intrusion cases (McHugh et al., 2011). Generally, the most significant question that must be answered in vapour intrusion is the origin of the contaminant (in-situ source vs. vapour migration from a contaminant plume). A particular challenge of using CSIA in vapour intrusion studies is obtaining a sufficient analyte mass for isotope analysis. The performance of different adsorbents was tested for analyte preconcentration from air before CSIA for benzene, PCE and TCE (Klisch et al., 2012). Collection of organic compounds for CSIA from indoor air have been carried out by pumping the air through sorbent tubes packed with adsorbents such as Tenax GR/Carboxen 569, and by bubbling the air through methanol, both with very good results (McHugh et al., 2011; Bouchard and Hunkeler, 2013). These two approaches involved active sampling, which requires power sources and trained personnel. More importantly, collecting multiple samples in parallel using active techniques can be prohibitively expensive and impractical. Finally, this type of sampling is representative only for the short sampling period studied and does not take into account longer-term changes in vapour exchange between the building and its exterior. Passive sampling allows longer sampling (up to several weeks) (Seethapathy et al., 2008; Górecki and Namieśnik, 2002), therefore the collected sample is more representative of the variable conditions inside buildings.

A permeation passive sampler developed at the University of Waterloo and commercialized under the name Waterloo Membrane Sampler (WMS) (Seethapathy and Górecki, 2011) opens the possibility of using passive sampling to collect enough organic contaminant mass for CSIA. The objective of this study was to evaluate the suitability of the WMS for preconcentration of organic compounds before CSIA, with future intended applications including collection of vapour samples from the unsaturated zone and indoor air. This was accomplished by exposing the samplers under controlled conditions to a standard gas mixture containing hexane, toluene and trichloroethene. The effects of time of exposure, amount collected and exposure temperature in isotopic fractionation were evaluated, and the method was tested at a field side (Sihota et al., 2013).

\section{Experimental}

\subsection{Materials}

The test analytes used in the study were hexane, benzene and trichloroethene, representing n-alkanes, aromatic hydrocarbons and chlorinated hydrocarbons, respectively. These chemical classes are typically found in vapour intrusion studies. High purity analytical grade chemicals were procured from Sigma-Aldrich, Canada. A standard gas mixture was generated using a gas cylinder purchased from Scott Specialty Gases, USA. In the cylinder, each compound had a concentration of $\sim 100 \mathrm{ppm}$ in nitrogen.

\subsection{WMS}

The WMS, commercially available from SiREM Labs (Guelph, ON, Canada), is based on a $1.8 \mathrm{~mL}$ standard crimp-top chromatographic autosampler vial that is partly filled with a sorbent and sealed with a polydimethylsiloxane (PDMS) 
membrane replacing the standard septum. The sorbent used in the experiments was Carbopack $\mathrm{B}^{\circledR}(180 \mathrm{mg}, 60 / 80 \mathrm{mesh})$ purchased from Sigma-Aldrich, Canada. PDMS membrane with strictly controlled thickness was prepared in the laboratory by mixing silicone elastomer base with silicone elastomer curing agent and by using spin coating technique. The raw materials for PDMS membrane were procured from Dow Corning, USA (SYLGARD ${ }^{\circledR} 184$ SILICONE ELASTOMER KIT). The precision spin coater, Cee ${ }^{\circledR}$ model 200X, was purchased from Brewer Science, Inc. The spin process was run for $60 \mathrm{~s}$ at $624 \mathrm{rpm}$. The thickness of the PDMS membrane produced was verified through weighing of a random sampling of membranes cut to the desired size with a die, with the target weight for a $100 \mu \mathrm{m}$ thick membrane being $8.0 \pm 0.5 \mathrm{mg}$ for the sampler based on the $1.8 \mathrm{~mL}$ vial (Seethapathy, 2009).

\subsection{Instrumentation}

\subsubsection{Thermal desorption unit}

Thermal desorption was performed using an ATD 400 Thermal Desorber (Perkin Elmer) equipped with a carousel that holds up to 50 TD tubes. The TD tube containing the sample was sealed with caps and installed on the ATD carousel. For the analysis, the TD tube was purged of air by a flow of helium, and then heated to desorption temperature for a predetermined time (primary desorption). The volatiles liberated from the sorbent were sent to a cold trap containing an adsorbent for refocusing. Once the sorbent desorption was complete, the cold trap was heated and the analytes were transferred to the $\mathrm{GC}$ for analysis (ATD, 1991). In this research, the desorption temperature of $250^{\circ} \mathrm{C}$ was held for $1.5 \mathrm{~min}$. After $65 \mathrm{~s}$ of purging the TD tube, the volatile chemicals were sent to the cold trap set at $-30^{\circ} \mathrm{C}$. The cold trap was then heated to $280^{\circ} \mathrm{C}$ for sample injection into the GC column. Split operation was used, with $10 \%$ of the sample from the TD tube reaching the GC column. In the experiments, the flows for the thermal desorber were set at $1 \mathrm{~mL} / \mathrm{min}$ for the column, $50 \mathrm{~mL} / \mathrm{min}$ for the primary desorption and $10 \mathrm{~mL} / \mathrm{min}$ for the secondary desorption split. They were set using an electronic flow meter (ADM2000 Universal Gas Flowmeter) purchased from Agilent Technologies, USA. For the conditioning of the sorbent, the TD tubes were heated to $250^{\circ} \mathrm{C}$ for $3 \mathrm{~min}$ with helium flowing through them (ATD, 1991). Tube blanks were analyzed to confirm the cleanliness of the sorbent.

\subsubsection{TD tubes}

Stainless steel TD tubes (90 mm long, $6.35 \mathrm{~mm}$ O.D.) were purchased from Perkin Elmer, Canada. They were filled with Carbopack $B^{\circledR}$ sorbent $(0.2 \mathrm{~g})$. The tubes were capped with PTFE caps and glass wool plugs were used with minimal compression at both ends.

\subsubsection{GC-IRMS}

Chromatographic separation of the analytes desorbed from the TD tube was carried out using an Agilent $6890 \mathrm{GC}$ (Agilent Technologies Inc.) equipped with a $60 \mathrm{~m} \times 0.32 \mathrm{~mm} \times 1.0 \mu \mathrm{m}$ RXI-1MS column. The GC oven temperature was held isothermally at $40^{\circ} \mathrm{C}$ for $5 \mathrm{~min}$, then ramped to $125^{\circ} \mathrm{C}$ at $20^{\circ} \mathrm{C} / \mathrm{min}$ and held for $1 \mathrm{~min}$, followed by a secondary temperature ramp to $250{ }^{\circ} \mathrm{C}$ at $30{ }^{\circ} \mathrm{C} / \mathrm{min}$ and held for $1 \mathrm{~min}$. The flow of the carrier gas was controlled by the TD unit. The separated compounds eluting from the GC column were transferred to the IRMS for carbon isotope analysis. The IRMS used in the study was a Micromass IsoPrime (Micromass UK Ltd.) mass spectrometer equipped with MassLynx software.

\subsubsection{TD-GC-IRMS calibration}

TD-GC-IRMS calibration was performed by preparing a standard gas mixture containing all three compounds of interest in a $1 \mathrm{~L}$ Tedlar bag filled with air. The volumes of the standards injected were $1 \mu \mathrm{L}$ hexane, $1 \mu \mathrm{L}$ benzene and $3 \mu \mathrm{L}$ TCE. The $\delta^{13} \mathrm{C}$ values for internal laboratory standards used were $-27.10 \%,-28.40 \%$ and $-31.40 \%$ for hexane, benzene and TCE, respectively. Concentrations of the chemicals in the Tedlar bag remained constant, and different standard gas mixture volumes were injected directly into the TD tubes. Prior to injection, the TD tubes were conditioned. A five-point calibration curve was generated and the final $\delta^{13} \mathrm{C}$ values for the standards were reported after normalization. Normalization in this case was based on polynomial regression with the intercept and slope used to correct the measured values to the internal laboratory standards run under the same conditions. This calibration method was used in all experiments in the study.

In order to evaluate the detection limit of the TD-GC-IRMS system, a standard gas mixture with concentrations of 0.65 , 0.88 and $4.38 \mathrm{mg} / \mathrm{m}^{3}$ for hexane, benzene and TCE, respectively, was prepared in the $1 \mathrm{~L}$ Tedlar bag. The corresponding masses for each analyte in the bag were $655 \mathrm{ng}$ for hexane, $880 \mathrm{ng}$ for benzene and $4380 \mathrm{ng}$ for TCE. The smallest volume of the standard gas mixture injected into the TD tube that produced a minimum acceptable analytical response (signal intensity) expressed in $\mathrm{nA}$ (nanoampere) and referred to as "peak height" throughout the study was $1 \mathrm{~mL}$, corresponding to 655,880 and $4380 \mathrm{pg}$ of the three analytes, respectively. The minimum peak height with which $\delta^{13} \mathrm{C}$ values could be calculated with adequate confidence was $1 \mathrm{nA}$. The test using $1 \mathrm{ml}$ of standard gas mixtures showed analytical reproducibility within $\pm 0.5 \%$ o $(n=5)$ (Table 1$)$. In most of the isotope measurements carried out in the study, the volumes of the standards were adjusted such that the IRMS peak heights fell between 2 and $10 \mathrm{nA}$, the optimum range for the instrument. 
Table 1

$\delta^{13} \mathrm{C}$ and analytical response values obtained for each analyte $(n=5)$ for $1 \mathrm{~mL}$ volume of standard gas mixture injected into the TD-GC-IRMS system.

\begin{tabular}{lllll}
\hline Compound & Average $\delta^{13} \mathrm{C}(\%)$ & $\begin{array}{l}\text { Std. dev. }(\%) \text { for } \\
\delta^{13} \mathrm{C} \text { values }\end{array}$ & $\begin{array}{l}\text { Analytical response } \\
\text { peak height }(\mathrm{nA})\end{array}$ & $\begin{array}{l}\text { Std. dev. }(\%) \text { for } \\
\text { peak height values }\end{array}$ \\
\hline Hexane & -30.9 & 0.30 & 1.13 & 0.20 \\
Benzene & -29.7 & 0.40 & 1.96 & 0.60 \\
TCE & -34.5 & 0.30 & 1.66 & 0.60 \\
\hline
\end{tabular}

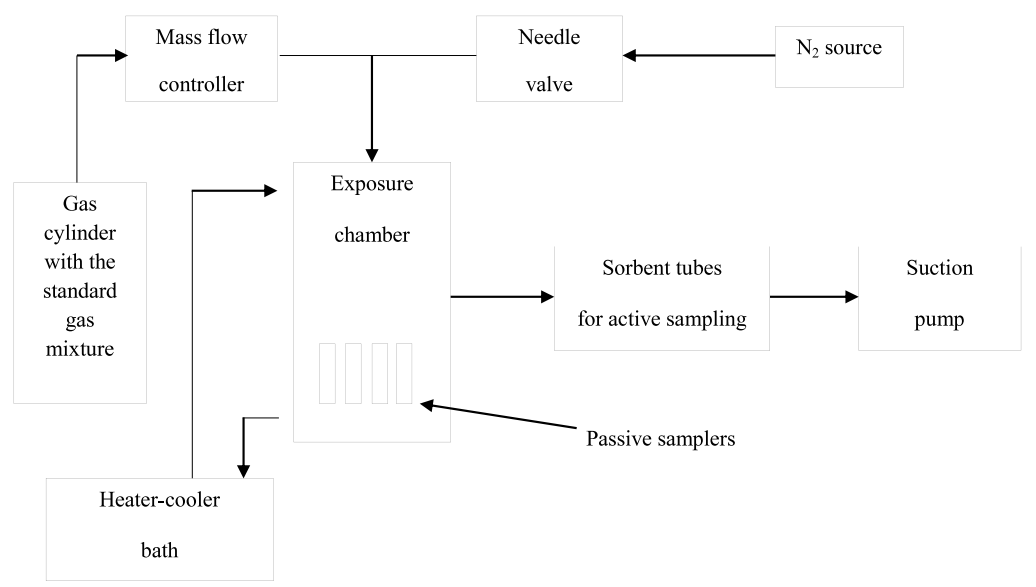

Fig. 1. Schematic diagram of the experimental setup. The heater-cooler bath was used only in the experiments on temperature effect.

\subsubsection{Experimental setup}

The purpose of the experimental setup (Fig. 1) was to generate a standard test gas with constant analyte concentrations. The setup allowed the determination of $\delta^{13} \mathrm{C}$ for gases collected by both passive and active sampling. Each chemical in the standard gas mixture inside the cylinder had a concentration of $\sim 100 \mathrm{ppm}$ in nitrogen. Nitrogen gas was used to dilute the standard gas mixture, which was delivered to the exposure chamber at controlled flow rates. The flow rate of the standard gas mixture was controlled by a mass flow controller, while the flow rate of the nitrogen dilution gas was controlled by a needle valve. Both flows were adjusted according to the requirements of a given study.

Prior to each exposure, the chamber was conditioned with the gas mixture for $1 \mathrm{~h}$. Exposure times for WMS varied depending on the study. During the passive sampling exposures, active sampling was performed periodically with sorption tubes using a suction pump (High Flo Gold Series pump) purchased from Canadian Tire, Waterloo, Canada. Active samples were collected from the outlet of the exposure chamber, hence the passive samplers placed inside of it were not affected. The flow of the suction pump was measured using a flow meter and different volumes were collected depending on the concentration of the standard gas mixture inside the exposure chamber at the time of sampling. For each exposure, active sampling used TD tubes packed with fresh Carbopack B sorbent, and passive sampling used new WMS fabricated in our laboratory. The effects of three parameters on ${ }^{13} \mathrm{C}$ values obtained through passive and active sampling for the three analytes were examined for this study: time of sampler exposure, analyte amount collected and exposure temperature. In each experiment, 4 passive samplers were exposed at the same time and 3 TD tubes were used for active sampling.

After completion of the exposure, $\delta^{13} \mathrm{C}$ values for passive and active methods for the three analytes were measured using the setup for TD-GC-IRMS mentioned previously.

\subsection{Methods}

\subsubsection{Effect of the WMS exposure time on $\delta^{13} \mathrm{C}$ values of the analytes collected by the sampler}

Experiments were performed at room temperature $\left(25^{\circ} \mathrm{C}\right)$ and the concentration in the exposure chamber was adjusted for each exposure time so that the analyte amount collected by the passive sampler was always the same. The times of exposures were $3,6,12,24,48,96$ and $192 \mathrm{~h}$, and the corresponding concentrations of the standard gas mixture in the exposure chamber were $6,3,1.5,0.75,0.375,0.1875$ and $0.09375 \mathrm{mg} / \mathrm{m}^{3}$. The volumes of the standard gas mixture collected through active sampling were $240,480,960,1920,3840,7680$ and $15360 \mathrm{~mL}$, respectively.

\subsubsection{Effect of the amount of analyte collected by the WMS on the $\delta^{13} \mathrm{C}$ values of the analytes collected by the sampler}

Experiments were performed at room temperature, and exposure times were 3, 6, 12, 24, 48 and $96 \mathrm{~h}$. To achieve an increase in the analyte amount collected by the sorbent in the WMS, the concentration inside the exposure chamber was 


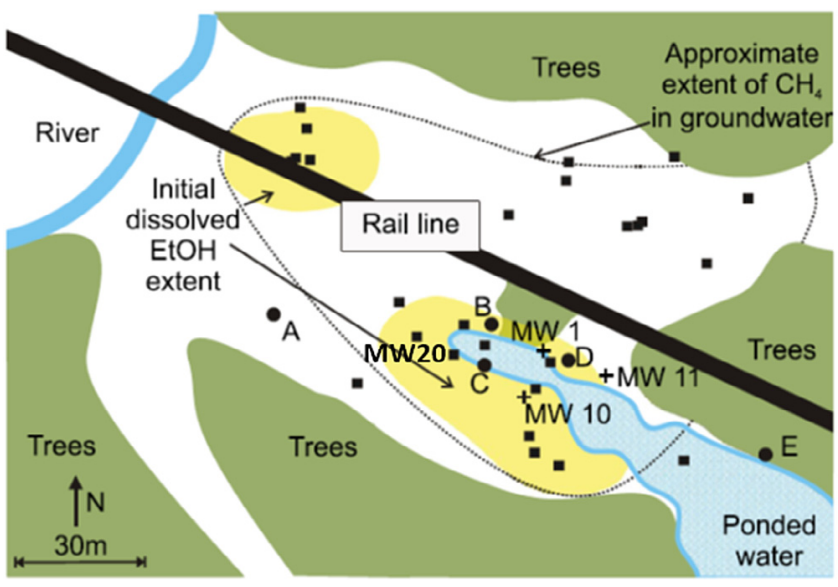

Fig. 2. Plan view of the field test site (Sihota et al., 2013). Samples for this research were collected from wells C, D and E.

maintained constant at $6 \mathrm{mg} / \mathrm{m}^{3}$ throughout the experiments. The volume of the standard gas mixture collected by active sampling was $240 \mathrm{~mL}$ for each exposure time.

\subsubsection{Effect of the WMS exposure temperature on $\delta^{13} \mathrm{C}$ values of the analytes collected by the sampler}

The experimental setup described in Section 2.3.5 was used. For the experiments, the exposure chamber was wrapped with a thin flexible plastic tube and insulation foam. The plastic tube was connected to a circulating bath with programmable temperature controller purchased from VWR, USA. The circulating bath temperature was adjusted to $4{ }^{\circ} \mathrm{C}$, so that the temperature inside the exposure chamber could be maintained constant at $12{ }^{\circ} \mathrm{C}$ throughout all experiments. All parameters (time, concentration and volume) were the same as in Section 2.4.1, except that the $192 \mathrm{~h}$ exposure time was not used in this study.

\subsection{Field study site}

The test site was located in the Minnesota River valley near the city of Cambria. This site was impacted by a multi-railcar derailment in November 2006, which released $\sim 95,000 \mathrm{~L}$ ( $\sim 25,000$ gallons) of DFE (ethanol denatured with 5\% gasoline). The site has been extensively studied during the recent years to evaluate production and fluxes of $\mathrm{CH}_{4}$ and $\mathrm{CO}_{2}$ associated with the ethanol spill (Sihota et al., 2013; Spalding et al., 2011). Passive samplers were deployed in the unsaturated zone for three weeks at different depths at three locations (C, D and E, Fig. 2). Benzene and toluene concentrations in the groundwater near the gas probes were below $10 \mu \mathrm{g} / \mathrm{L}$. A groundwater sample was collected from well MW20 in an area with relatively high benzene and toluene concentrations to evaluate the carbon isotopic composition of these compounds in the saturated zone.

\section{Results and discussion}

\subsection{Effect of the WMS exposure time on $\delta^{13} \mathrm{C}$ values}

The effects of exposure time on $\delta^{13} \mathrm{C}$ values measured by TD-GC-IRMS using both WMS sampling and active sampling for analyte collection were evaluated and compared. Two sets of experiments were performed under the same conditions. The $\delta^{13} \mathrm{C}$ results obtained from both experiments for passive and active sampling are presented in Table 2. The data for both studies showed that the results were consistent and reproducible with standard deviations within the accepted error of $\pm 0.5 \%$ for all compounds. The data also showed that the $\delta^{13} \mathrm{C}$ values for passive sampling tended to be more depleted than the values obtained with active sampling (Fig. $3(\mathrm{~A})-(\mathrm{C})$ ).

This pattern was observed for all three compounds. The isotopic differences, due to isotopic fractionation, ranged from 0.9 to $1.4 \%$ (Table 2). The magnitude of the isotopic fractionation was constant and independent of the exposure time (within the range of times examined), as shown in Fig. 3(A)-(C), where the slopes of the lines of best fit were close to zero and $R^{2}$ values were very small. In order to determine if these differences were significant, one tailed Student's $t$ test was applied at $95 \%$ confidence level. From the $t$ test analysis it was determined that for all compounds $t_{\text {stat }}>t_{\text {critical_one-tail }}$, meaning that the differences between the $\delta^{13} \mathrm{C}$ values were significant. The probabilities that these differences were due to random factors were $1.6 \times 10^{-7}$ and $4.9 \times 10^{-6}$ for hexane for the first and the second study, respectively, $2.6 \times 10^{-7}$ and $5.2 \times 10^{-8}$ for benzene, and $2 \times 10^{-4}$ for both studies for TCE. 


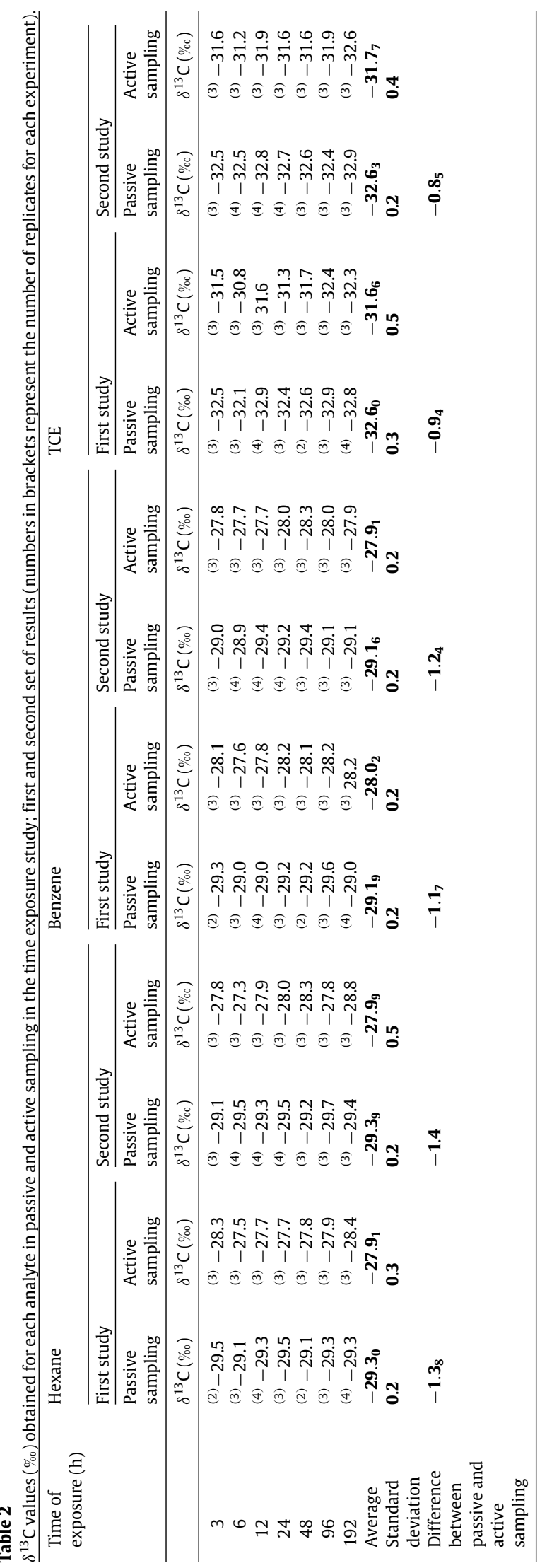


A

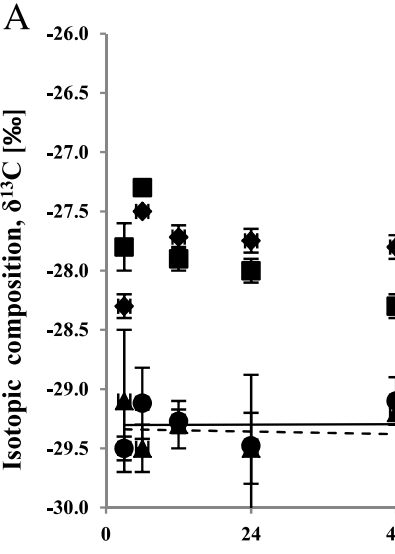

B

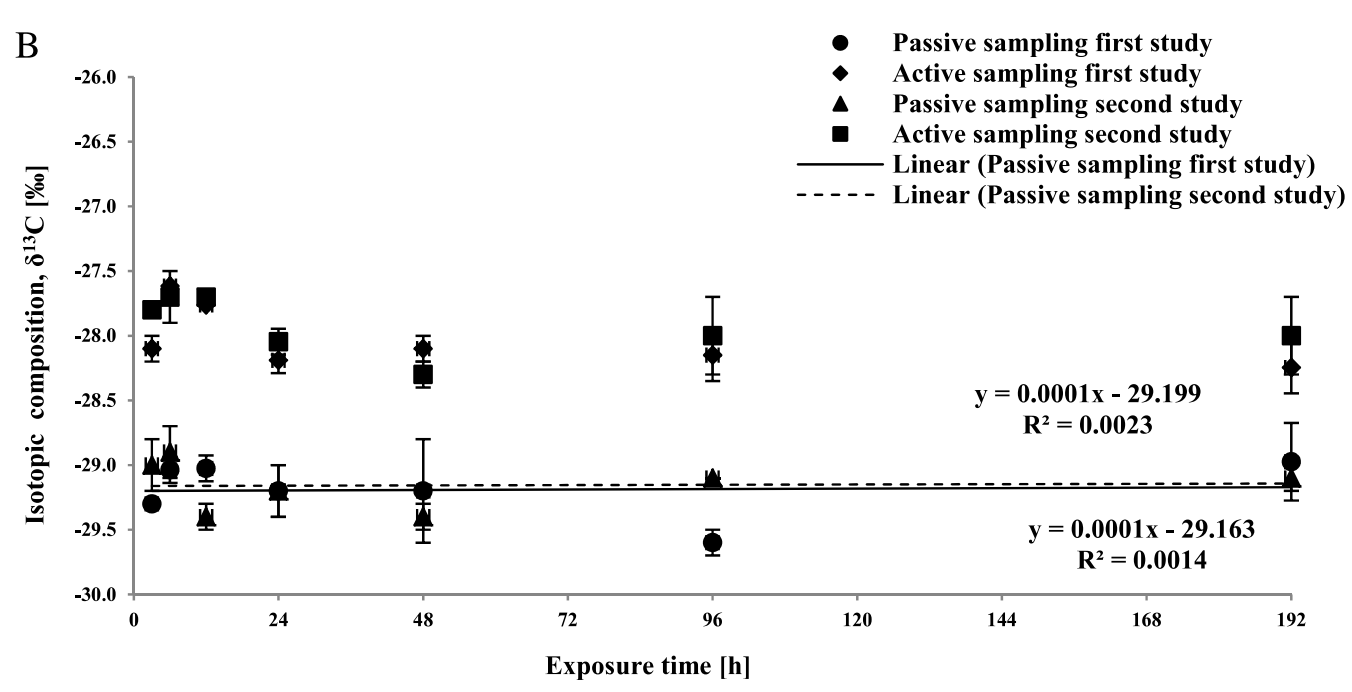

- Passive sampling first study

- Active sampling first study

- Passive sampling second study

- Active sampling second study

Linear (Passive sampling first study)

- - - - Linear (Passive sampling second study)

Exposure time [h]

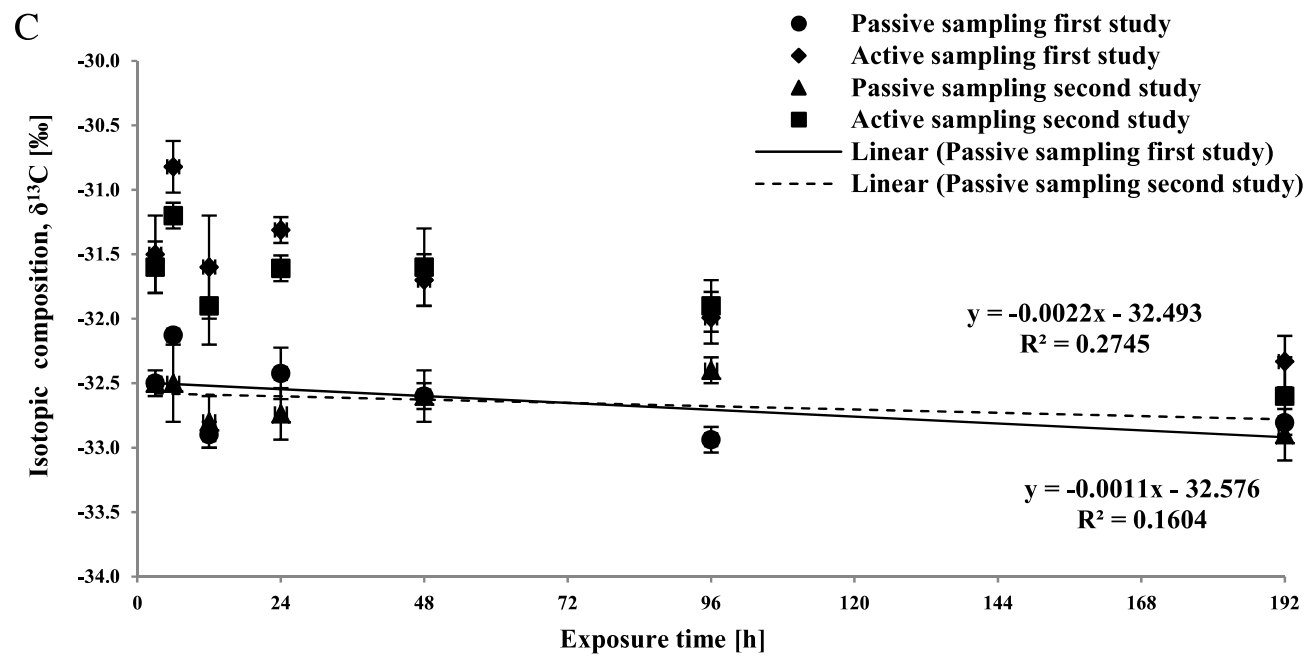

Fig. 3. $\delta^{13} \mathrm{C}$ values obtained in the time of exposure studies for (A.) hexane, (B.) benzene and (C.) trichloroethene (TCE). The solid lines are the lines of best fit.

There are many factors that might cause isotopic fractionation; however, in this study the only process that could cause this phenomenon was permeation of the analytes through the PDMS membrane. The data indicated that the difference was practically constant for all the analytes and independent of the exposure time (Table 2 and Fig. 3). 
Table 3

$\delta^{13} \mathrm{C}$ values (\%o) obtained for each analyte for passive and active sampling when the amount collected by WMS was increased with each exposure time (the numbers in brackets represent the number of replicates for each experiment).

\begin{tabular}{|c|c|c|c|c|c|c|}
\hline Time of exposure (h) & $\begin{array}{l}\text { Passive } \\
\text { sampling } \\
\text { Hexane }\end{array}$ & $\begin{array}{l}\text { Active } \\
\text { sampling } \\
\text { Hexane }\end{array}$ & $\begin{array}{l}\text { Passive } \\
\text { sampling } \\
\text { Benzene }\end{array}$ & $\begin{array}{l}\text { Active } \\
\text { sampling } \\
\text { Benzene }\end{array}$ & $\begin{array}{l}\text { Passive } \\
\text { sampling } \\
\text { TCE }\end{array}$ & $\begin{array}{l}\text { Active sampling } \\
\text { TCE }\end{array}$ \\
\hline & $\delta^{13} \mathrm{C}$ & $\delta^{13} \mathrm{C}$ & $\delta^{13} \mathrm{C}$ & $\delta^{13} \mathrm{C}$ & $\delta^{13} \mathrm{C}$ & $\delta^{13} \mathrm{C}$ \\
\hline 3 & (3) -30.2 & (2) -27.9 & (3) -29.5 & (2) -28.0 & (3) -33.2 & (2) -32.0 \\
\hline 6 & (3) -29.4 & (3) -27.9 & (3) -29.3 & (3) -28.0 & (3) -31.9 & (3) -32.1 \\
\hline 12 & (4) -29.7 & (3) -27.1 & (4) -29.4 & (3) -28.2 & (4) -32.8 & (3) -31.8 \\
\hline 24 & (4) -29.5 & (3) -27.7 & (4) -29.1 & (3) -28.0 & (4) -32.9 & (3) -31.8 \\
\hline 48 & (4) -29.9 & (3) -27.8 & (4) -29.0 & (3) -28.3 & (4) -32.9 & (3) -32.2 \\
\hline 96 & (4) -29.5 & (3) -28.2 & (4) -28.5 & (3) -28.0 & (4) -32.8 & (3) -31.5 \\
\hline Average & $-29.7_{0}$ & $-27.7_{6}$ & $-29.1_{3}$ & $-28.0_{8}$ & $-32.7_{5}$ & $-31.9_{0}$ \\
\hline Standard deviation & 0.3 & 0.4 & 0.4 & 0.1 & 0.4 & 0.3 \\
\hline $\begin{array}{l}\text { Difference between passive and } \\
\text { active sampling }\end{array}$ & $-1.9_{3}$ & & $-1.0_{5}$ & & $-0.8_{5}$ & \\
\hline
\end{tabular}

Two factors leading to isotope fractionation during permeation must be considered: diffusion through and partitioning into and out of the PDMS membrane (Stable, 2004). Lighter isotopes diffuse faster than heavier isotopes, making them separate from one another. In addition, compounds containing heavier isotopes typically have lower partition coefficients in PDMS. It is well known, for example, that in gas chromatography compounds labelled with heavier isotopes elute earlier compared to compounds with lighter isotopes (Meier-Augenstein, 1999). Both these phenomena could explain the $\delta^{13} \mathrm{C}$ values obtained through passive sampling, which were depleted in ${ }^{13} \mathrm{C}$ relative to ${ }^{12} \mathrm{C}$ isotopes when compared with the $\delta^{13} \mathrm{C}$ values obtained with active sampling.

\subsection{Effect of the analyte amount collected by the WMS on $\delta^{13} \mathrm{C}$ values}

In this study, the effect of the quantity of the analyte collected by the WMS on $\delta^{13} \mathrm{C}$ was analyzed and compared with $\delta^{13} \mathrm{C}$ obtained through active sampling. To accomplish this, the analyte concentrations in the exposure chamber were kept constant, while the exposure time of the passive samplers was varied. The results obtained in this study are listed in Table 3.

The data in Table 3 were very consistent and reproducible, and the standard deviations, ranging from $\pm 0.1 \%$ to $\pm 0.4 \%$, were within the accepted error for all compounds. These data also showed that the $\delta^{13} \mathrm{C}$ values for passive sampling tended to be more depleted than the values obtained with active sampling. Statistical analysis using one tailed, paired Student's $t$ test at $95 \%$ confidence level showed that in all cases $t_{\text {stat }}$ was greater than $t_{\text {critical one-tail }}$ for all the analytes, meaning the isotopic differences between the $\delta^{13} \mathrm{C}$ values between passive and active sampling during both exposures were significant. The probabilities that the differences were due to random factors were $8.3 \times 10^{-7}$ for hexane, $2.7 \times 10^{-5}$ for benzene and $1 \times 10^{-3}$ for TCE. Similarly to the previous experiment, the magnitude of isotopic fractionation was constant and independent of the amount collected by the WMS sorbent within the range examined.

In addition, the magnitude of isotopic fractionation observed in this study was compared to values obtained in the previous experiment (effect of the exposure time) using two tailed paired Student's $t$ test at 95\% confidence level. With one exception, $t_{\text {stat }}$ was lower than $t_{\text {critical two-tail }}$, meaning that no significant differences were observed between the isotopic fractionation observed in both experiments. The exception was hexane, for which the difference was found to be borderline significant $(p=0.004)$. However, it should be pointed out that instrumental problems were encountered when determining $\delta^{13} \mathrm{C}$ for hexane, therefore this result should be treated as tentative. Fig. 4 presents the $\delta^{13} \mathrm{C}$ values obtained for each analyte in this study as a function of time. No dependence between the two variables was observed.

\subsection{Effect of the WMS exposure temperature on $\delta^{13} \mathrm{C}$ values}

Previous research demonstrated that WMS uptake rates increased with decreasing temperature (Seethapathy and Górecki, 2010). Consequently, a study on the effect of temperature on $\delta^{13} \mathrm{C}$ values measured by the WMS was also conducted (Table 4).

The $\delta^{13} \mathrm{C}$ values obtained at $12{ }^{\circ} \mathrm{C}$ were consistent, reproducible and with standard deviations within the accepted error for all the chemicals. Similarly to the other experiments, an isotopic difference was observed between passive and active sampling. In order to determine if the exposure temperature influenced the isotopic fractionation obtained in this study, the results were statistically compared with the isotopic fractionation results determined in the time of exposure study, in which the experiments were performed under the same conditions at room temperature. Statistical testing using a two tailed paired Student's $t$ test at $95 \%$ confidence level found that $t_{\text {stat }}<t_{\text {critical two-tail }}$ for all the analytes, meaning that no significant differences were observed between isotopic fractionation obtained at two different temperatures. The magnitude of isotopic fractionation was thus found to be constant with time and independent of the exposure temperature between 12 and $25^{\circ} \mathrm{C}$. 


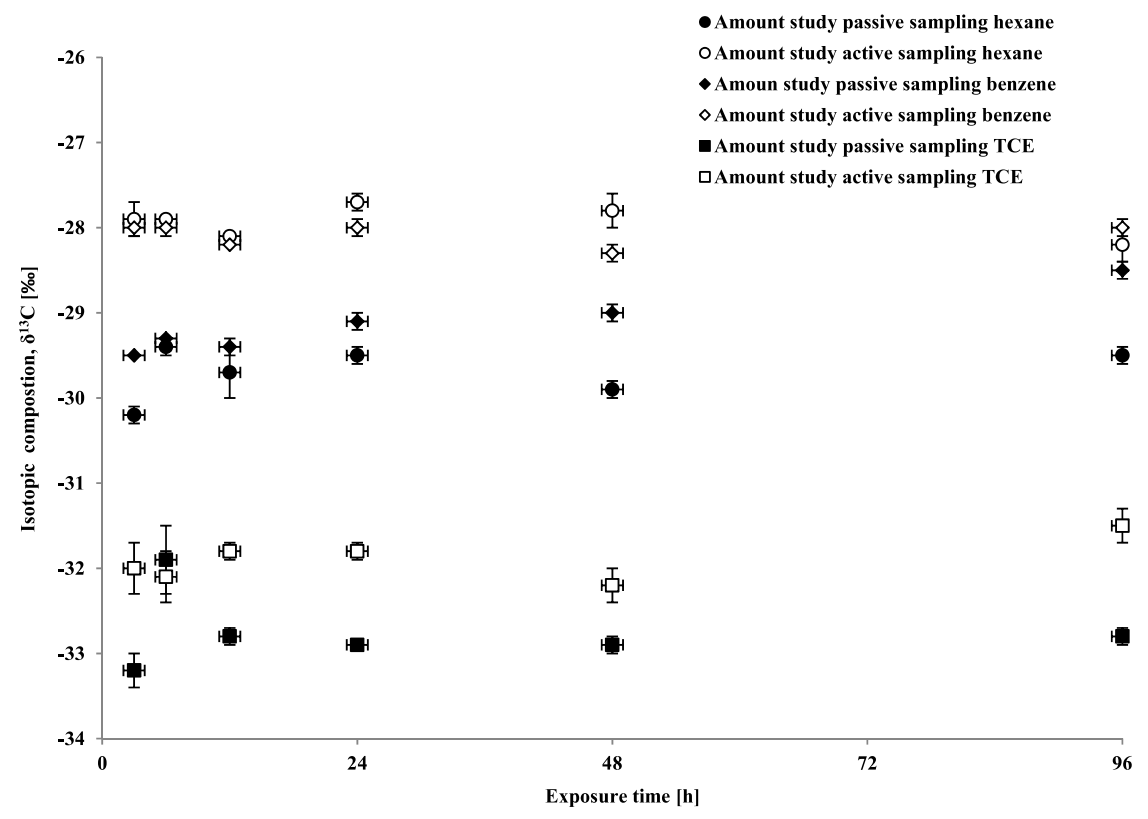

Fig. 4. $\delta^{13} \mathrm{C}$ values for hexane, benzene and TCE obtained when the analyte amount collected by the WMS increased with exposure time.

Table 4

$\delta^{13} \mathrm{C}$ values (\%) obtained for each analyte for passive and active sampling when the temperature in the exposure chamber was $12{ }^{\circ} \mathrm{C}($ the numbers in brackets represent the number of replicates for each experiment).

\begin{tabular}{|c|c|c|c|c|c|c|}
\hline Time of exposure (h) & $\begin{array}{l}\text { Passive } \\
\text { sampling } \\
\text { Hexane }\end{array}$ & $\begin{array}{l}\text { Active } \\
\text { sampling } \\
\text { Hexane }\end{array}$ & $\begin{array}{l}\text { Passive } \\
\text { sampling } \\
\text { Benzene }\end{array}$ & $\begin{array}{l}\text { Active } \\
\text { sampling } \\
\text { Benzene }\end{array}$ & $\begin{array}{l}\text { Passive } \\
\text { sampling } \\
\text { TCE }\end{array}$ & $\begin{array}{l}\text { Active sampling } \\
\text { TCE }\end{array}$ \\
\hline & $\delta^{13} \mathrm{C}$ & $\delta^{13} \mathrm{C}$ & $\delta^{13} \mathrm{C}$ & $\delta^{13} \mathrm{C}$ & $\delta^{13} \mathrm{C}$ & $\delta^{13} \mathrm{C}$ \\
\hline 6 & (3) -29.2 & (3) -28.1 & (3) -29.0 & (3) -27.4 & (3) -32.8 & (3) -32.3 \\
\hline 1 & (4) -29.2 & (3) -28.1 & (4) -29.3 & (3) -28.1 & (4) -32.7 & (3) -31.6 \\
\hline 24 & (4) -29.0 & (3) -28.1 & (4) -28.6 & (3) -27.4 & (4) -31.9 & (3) -31.4 \\
\hline 48 & (4) -29.5 & (3) -27.5 & (4) -29.1 & (3) -28.2 & (4) -32.4 & (3) -32.0 \\
\hline 96 & (2) -29.1 & (2) -28.0 & (2) -28.6 & (2) -28.5 & (2) -32.1 & (2) -32.4 \\
\hline Average & $-29.2_{0}$ & $-27.9_{6}$ & $-28.9_{2}$ & $-27.9_{2}$ & $-32.3_{8}$ & $-31.9_{4}$ \\
\hline Standard deviation & 0.2 & 0.3 & 0.3 & 0.5 & 0.4 & 0.4 \\
\hline $\begin{array}{l}\text { Difference between passive and } \\
\text { active sampling }\end{array}$ & $-1.2_{4}$ & & $-\mathbf{1 . 0}_{1}$ & & $-0.4_{4}$ & \\
\hline
\end{tabular}

Table 5

Hexane, benzene and TCE analytical response measured at different temperatures.

\begin{tabular}{|c|c|c|c|c|c|c|}
\hline \multirow{2}{*}{$\begin{array}{l}\text { Exposure } \\
\text { times }(\mathrm{h})\end{array}$} & \multicolumn{2}{|l|}{ Hexane } & \multicolumn{2}{|l|}{ Benzene } & \multicolumn{2}{|l|}{ TCE } \\
\hline & $\begin{array}{l}\text { Analytical response } \\
(\mathrm{nA}) \\
\text { Room temperature }\end{array}$ & $\begin{array}{l}\text { Analytical } \\
\text { response (nA) } \\
\text { Low temperature }\end{array}$ & $\begin{array}{l}\text { Analytical response } \\
(\mathrm{nA}) \\
\text { Room temperature }\end{array}$ & $\begin{array}{l}\text { Analytical } \\
\text { response }(\mathrm{nA}) \\
\text { Low temperature }\end{array}$ & $\begin{array}{l}\text { Analytical response } \\
(\mathrm{nA}) \\
\text { Room temperature }\end{array}$ & $\begin{array}{l}\text { Analytical response } \\
\text { (nA) } \\
\text { Low temperature }\end{array}$ \\
\hline 6 & 2.8 & 5.7 & 8.3 & 10.6 & 11.1 & 14 \\
\hline 3 & 2.2 & 3.2 & 6.7 & 9.5 & 8.1 & 12.4 \\
\hline 24 & 2.3 & 4.0 & 6.7 & 10.9 & 8.2 & 12.9 \\
\hline 48 & 2 & 2.8 & 5.7 & 7.7 & 6.9 & 9.8 \\
\hline 96 & 1.9 & 3.5 & 4.6 & 7.7 & 5.2 & 8.0 \\
\hline
\end{tabular}

Although temperature did not affect the isotopic fractionation, it did affect the analytical instrument response. This can be explained by the temperature dependence of the PDMS permeability towards each chemical. Permeation is a temperaturedependent process, as the diffusion coefficients in PDMS decrease with decreasing temperature, while the partitioning coefficients increase (Seethapathy and Górecki, 2010). As seen in Table 5, for each chemical and each exposure time, the TDGC-IRMS peak height measured increased at lower temperature, pointing to a higher amount sorbed. Lowering the exposure temperature to $12{ }^{\circ} \mathrm{C}$ did not affect the carbon isotopic composition for the analytes collected by WMS. Fig. 5 shows that $\delta^{13} \mathrm{C}$ values measured at lower temperature had no significant variations in relation to exposure time. 


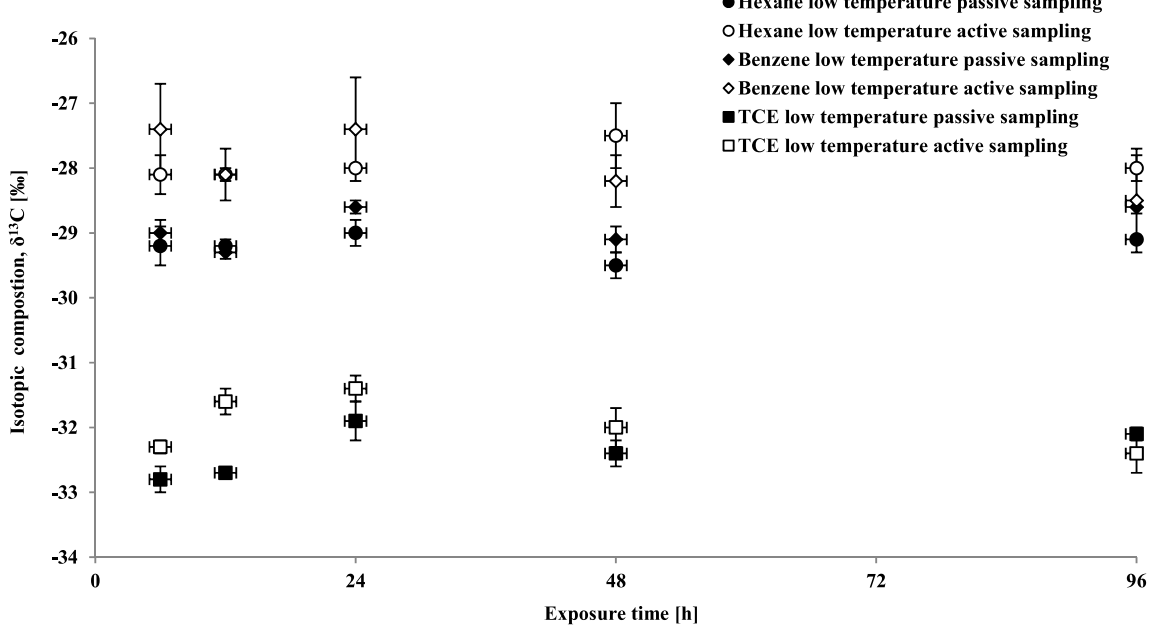

Fig. 5. Hexane, benzene and TCE $\delta^{13} \mathrm{C}$ values obtained at $12{ }^{\circ} \mathrm{C}$ vs. exposure time.

Table 6

Carbon isotope data for benzene and toluene for the WMS and groundwater.

\begin{tabular}{llll}
\hline & Depth $(\mathrm{m})$ & Benzene $\delta^{13} \mathrm{C}(\% \mathrm{o})$ & Toluene $\delta^{13} \mathrm{C}(\% \mathrm{o})$ \\
\hline WMS & & & \\
Site C & 0.8 & -27.4 & -23.3 \\
& 1.0 & -28.30 & -24.4 \\
Site D & & & -22.9 \\
& 0.8 & & -22.2 \\
Site E & 1.0 & & -22.9 \\
& 0.8 & & -22.2 \\
& 1.0 & & -28.2 \\
Groundwater & & &
\end{tabular}

The results obtained were relevant with respect to the applicability of the WMS in field studies for carbon isotope analysis in soil gas contamination. The low temperature was purposely selected to be $12^{\circ} \mathrm{C}$ to represent a value close to temperatures encountered in soil gas sampling.

\subsection{Field evaluation}

The test site was located in the Minnesota River valley near the city of Cambria, as described in Section 2.5. The carbon isotopic composition of benzene and toluene in the groundwater was $-28.2 \%$ and $-27.7 \%$, respectively (Table 6 ). Benzene and toluene were not detected at shallow depths in all gas probes. Benzene was only detected at site C. The WMS isotope data showed $\delta^{13} \mathrm{C}$ values of $-27.4 \%$ and $-28.3 \%$ at 0.8 and $1.0 \mathrm{~m}$ for benzene at site C. Toluene showed $\delta^{13} \mathrm{C}$ values of $-23.3 \%$ and $-24.4 \%$ at 0.8 and $1.0 \mathrm{~m}$ at the same site. In case of sites $\mathrm{D}$ and $\mathrm{E}$, the isotope data showed $\delta^{13} \mathrm{C}$ values of $-22.9 \%$ and $-22.2 \%$ at 0.8 and $1.0 \mathrm{~m}$ for toluene (Table 6 ). The benzene ${ }^{13} \mathrm{C}$ data for gas in the unsaturated zone was very similar to the $\delta^{13} \mathrm{C}$ for the groundwater; however, taking into account the isotope effect associated with the passive sampler of around $1.4 \%$, benzene was enriched by roughly the same amount compared to the groundwater. The toluene data were very reproducible and showed much more enriched $\delta^{13} \mathrm{C}$ values than the $\delta^{13} \mathrm{C}$ value for the groundwater at all sites. The observed enrichment pattern was most likely associated with oxidation of the aromatic compounds during transport in the unsaturated zone (Bouchard et al., 2008). The field test demonstrated that WMS can be used to collect gas samples for CSIA in an unsaturated zone contaminated with gasoline compounds with reproducible results. Further studies are needed to test this method at sites contaminated with complex mixtures of chlorinated compounds.

\section{Conclusions}

A WMS-TD-GC-IRMS method for the determination of the carbon isotopic composition of the contaminants in soil gas and vapor intrusion was successfully developed. The sampling processes introduced small isotopic fractionation in all cases; however, the degree of fractionation remained practically constant and independent of the sampling time, mass collected 
or exposure temperature in the ranges of variables examined. The results were very consistent, with standard deviations lower than $0.5 \%$. The WMS allows the determination of the carbon isotopic composition of the analytes at concentrations as low as $0.65 \mathrm{mg} / \mathrm{m}^{3}$ for hexane, $0.88 \mathrm{mg} / \mathrm{m}^{3}$ benzene and $4.38 \mathrm{mg} / \mathrm{m}^{3}$ for TCE. The results obtained in all studies showed good reproducibility and consistency, with standard deviations within the commonly accepted analytical error of $\pm 0.5 \%$. The field test showed that passive samplers can be used to collect gas samples from the unsaturated zone for CSIA analysis. As with any new method, this technique needs to be tested at sites contaminated by different mixtures of organic compounds spanning a wide range of concentrations. Nevertheless, this research could serve as a basis for future studies on the application of CSIA for fingerprinting in the determination of pollution sources in vapour intrusion or soil gas contamination studies.

\section{Acknowledgement}

The authors gratefully acknowledge funding from the ORF-RI program (RE-03-061).

\section{References}

ATD 400 User's Manual. 1991. Perkin Elmer Ltd., Beaconsfield, Buckinghamshire, England.

Blessing, M., Schmidt, T.C., Dinkel, R., Haderlein, S.B., 2009. Delineation of multiple chlorinated ethene sources in an industrialized area - A forensic field study using compound-specific isotope analysis. Environ. Sci. Technol. 43 (8), 2701-2707.

Bouchard, D., Hunkeler, D., 2013. Solvent-based dissolution method to sample gas-phase volatile organic compounds for compound specific isotope analysis. J. Chromatogr. A 1325, 16-22.

Bouchard, D., Hunkeler, D., Gaganis, P., Aravena, R., Höhener, P., Broholm, M.M., Kjeldsen, P., 2008. Carbon isotope fractionation during diffusion and biodegradation of petroleum hydrocarbons in the unsaturated zone: field experiment at Værløse Airbase, Denmark, and modeling. Environ. Sci. Technol. 42 (2), 596-601.

Chartrand, M.M.G., Morrill, P., Lacrampe-Couloume, G., Lollar, B.S., 2005. Stable isotope evidence for biodegradation of chlorinated ethenes at a fractured bedrock site. Environ. Sci. Technol. 39 (13), 4848-4856.

Górecki, T., Namieśnik, J., 2002. Passive sampling. TrAC 21 (4), 276-291.

Hunkeler, D., Aravena, R., Shouakar-Stash, O., Weisbrod, N., Nasser, A., Netzer, L., Ronen, D., 2011. Carbon and chlorine isotope ratios of chlorinated ethenes migrating through a thick unsaturated zone of a sandy aquifer. Environ. Sci. Technol. 45, 8247-8253.

Klisch, M., Kuder, T., Philp, R.P., McHugh, T.E., 2012. Validation of adsorbents for sample preconcentration in compound-specific isotope analysis of common vapor intrusion pollutants. J. Chromatogr. A 1270, 20-27.

Lojkasek-Lima, P., Aravena, R., Parker, B.L., Cherry, J.A., 2012a. Fingerprinting TCE in a bedrock aquifer using compound-specific isotope analysis. Ground Water 50 (5), 754-764.

Lojkasek-Lima, P., Aravena, R., Shouakar-Stash, O., Frape, S.K., Marchesi, M., Fiorenza, S., Vogan, J., 2012b. Evaluating TCE abiotic and biotic degradation pathways in a permeable reactive barrier using compound specific isotope analysis. Ground Water Monit. Rem. 32, 53-62.

McHugh, T., Kuder, T., Fiorenza, S., Gorder, K., Dettenmaier, E., Philp, P., 2011. Application of CSIA to distinguish between vapor intrusion and indoor sources of VOCs. Environ. Sci. Technol. 45 (14), 5952-5958.

Meier-Augenstein, W., 1999. Applied gas chromatography coupled to isotope ratio mass spectrometry. J. Chromatogr. A 842, $351-371$.

Patterson, B.M., Aravena, R., Davis, G.B., Furness, A.J., Bastow, T.P., Bouchard, D., 2014. Multiple lines of evidence to demonstrate vinyl chloride aerobic biodegradation in the vadose zone and factors controlling rates. J. Contam. Hydrol. 153, 69-77.

Seethapathy, S. 2009. (Ph.D. Thesis), University of Waterloo, Waterloo, Ontario, Canada.

Seethapathy, S., Górecki, T., 2010. Polydimethylsiloxane-based permeation passive sampler. Part II: Effect of temperature and humidity on the calibration constants. J. Chromatogr. A 1217, 7907-7913.

Seethapathy, S., Górecki, T., 2011. Polydimethylsiloxane-based permeation passive air sampler. Part I: Calibration constants and their relation to retention indices of the analytes. J. Chromatogr. A 1218 (1) 143-155.

Seethapathy, S., Górecki, T., Li, X., 2008. Passive sampling in environmental analysis. J. Chromatogr. A 1184, $234-253$.

Sihota, N.J., Mayer, K.U., Toso, M.A., Atwater, J.F., 2013. Methane emissions and contaminant degradation rates at sites affected by accidental releases of denatured fuel-grade ethanol. J. Contam. Hydrol. 151, 1-15.

Spalding, R.F., Toso, M.A., Exner, M.E., Hattan, G., Higgins, T.M., Sekely, A.C., Jensen, S.D., 2011. Long-term groundwater monitoring results at large sudden denatured ethanol releases. Ground Water Monit. Rem. 31, 69-81.

Stable, J.H., 2004. Isotope Geochemistry, revised and updated ed. Springer, Germany, p. 5. 5th. 